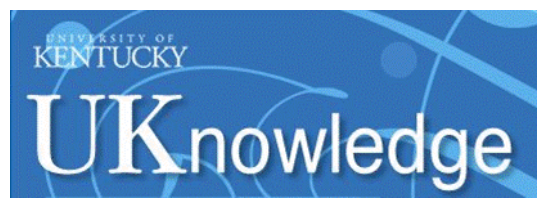

University of Kentucky

UKnowledge

\title{
Global Assessment of Grassland Carrying Capacities and Relative Stocking Densities of Livestock
}

\section{J. Piipponen}

Aalto University, Finland

M. Jalava

Aalto University, Finland

J. de Leeuw

Baku State University, Azerbaijan

\author{
A. Rizayeva \\ University of Wisconsin-Madison \\ C. Godde \\ CSIRO, Australia
}

See next page for additional authors

Follow this and additional works at: https://uknowledge.uky.edu/igc

Part of the Plant Sciences Commons, and the Soil Science Commons

This document is available at https://uknowledge.uky.edu/igc/24/2-2/31

The XXIV International Grassland Congress / XI International Rangeland Congress (Sustainable Use of Grassland and Rangeland Resources for Improved Livelihoods) takes place virtually from October 25 through October 29, 2021.

Proceedings edited by the National Organizing Committee of 2021 IGC/IRC Congress

Published by the Kenya Agricultural and Livestock Research Organization

This Event is brought to you for free and open access by the Plant and Soil Sciences at UKnowledge. It has been accepted for inclusion in International Grassland Congress Proceedings by an authorized administrator of UKnowledge. For more information, please contact UKnowledge@lsv.uky.edu. 


\section{Presenter Information}

J. Piipponen, M. Jalava, J. de Leeuw, A. Rizayeva, C. Godde, M. Herrero, and M. Kummu

This event is available at UKnowledge: https://uknowledge.uky.edu/igc/24/2-2/31 


\title{
Global assessment of grassland carrying capacities and relative stocking densities of livestock
}

\author{
Piipponen, J*; Jalava, M; de Leeuw, J; Rizayeva, A; Godde, C; Herrero, M; Kummu, M. \\ * Water and Development Research Group, Aalto University, Espoo, Finland; \\ $\uparrow$ Water and Development Research Group, Aalto University, Espoo, Finland; \\ $\uparrow$ Baku State University, Dept. of Bioecology, Baku, Azerbaijan; \\ $\dagger$ SILVIS Lab, Department of Forest and Wildlife Ecology, University of Wisconsin-Madison, \\ Madison, WI 53706, USA; \\ $\uparrow$ Commonwealth Scientific and Industrial Research Organisation, Australia; \\ $\uparrow$ Commonwealth Scientific and Industrial Research Organisation, Australia; \\ $\uparrow$ Water and Development Research Group, Aalto University, Espoo, Finland
}

Key words: livestock; carrying capacity; relative stocking density; overgrazing; grasslands

\begin{abstract}
Although many suggest that future diets should include more plant-based proteins, animal-sourced foods are unlikely to completely disappear from our diet. Grasslands yield a notable part of the world's animal protein production, but thus far, there is no global insight into the relationship between current livestock stocking densities and the availability of grassland forage resources. This inhibits acting upon concerns over the negative effects of overgrazing in some areas and utilising the potential for increasing production in others. Previous research has examined the potential of sustainable grazing but lacks generic and observation-based methods needed to fully understand the opportunities and threats of grazing. Here we provide a novel framework and method to estimate global livestock carrying capacity and relative stocking density, i.e. the reported livestock distribution relative to the estimated carrying capacity. We first estimate the aboveground biomass that is available for grazers on grasslands and savannas based on the MODIS Net Primary Production (NPP) approach on a global scale. This information is then used to calculate reasonable livestock carrying capacities, using slopes, forest cover and animal forage requirements as restrictions. With this approach, we found that stocking rates exceed the forage provided by grasslands in northwestern Europe, midwestern United States, southern China and the African Sahel. In this study, we provide the highest resolution global datasets to date. Our results have implications for prospective global food system modelling as well as national agricultural and environmental policies. These maps and findings can assist with conservation efforts to reduce land degradation associated with overgrazing and help identify undergrazed areas for targeted sustainable intensification efforts.
\end{abstract}




\section{Introduction}

The scientific literature expresses diverse opinions on the sustainability of livestock production on the grasslands of the world. Certain studies suggest that some of the livestock production relying on natural grasslands is sustainable from the point of view of natural resources and the environment (e.g. Holechek et al., 2010; Kemp and Michalk, 2007) and that significant areas of grassland are understocked and thus have potential to increase the production of livestock and animal proteins in these areas (Fetzel et al., 2017; Monteiro et al., 2020; Rolinski et al., 2018). However, other studies state that a notable fraction of the world's grasslands host livestock populations that exceed the carrying capacity with negative effects on the environment (Alkemade et al., 2013; Reid et al., 2009). These contrasting views do not necessarily contradict each other. Instead, they reflect a situation where some grasslands are overstocked, whilst in other situations, livestock utilizes grasslands according to or below their carrying capacity.

Depending on the definition, methods and assumptions, grasslands comprise $20-47 \%$ of the world's land area (Godde et al, 2018) and 80\% of agriculturally productive land (Gibson and Newman, 2019). Furthermore, they support the livelihood of around 800 million people (Suttie et al., 2005; Kemp et al., 2013). Grazing systems are diverse, ranging from nomadic pastoral activities in sub-Saharan native savannas to sedentary Dutch dairy farming on fertilized sown pastures (Godde et al., 2018). In some regions, vegetation adapted to extreme conditions and the species-rich population of the grasslands provide a buffer for the disadvantageous effects of climate change (Craine et al., 2013; Dengler et al., 2014; Tamburino et al., 2020). In fact, constitutive components of biodiversity such as pollinators are greatly dependent on these regions. However, moving away from traditional agricultural practices - such as extensive grazing and land use-jeopardizes grassland areas and their species (Estel et al., 2018; Gibson and Newman, 2019; Gossner et al., 2016).

Heavy stocking densities cause land degradation and desertification, which lead to land erosion, whereas properly managed moderate grazing can benefit the environment by providing ecosystem services, regulating the terrestrial carbon cycle and increasing the ecological resilience against natural disasters (Gibson and Newman, 2019; Lv et al., 2020). The importance of light or moderate grazing and especially rotational grazing has been extensively emphasized in the literature (Gibson and Newman, 2019; Holechek et al., 2010; Loeser et al., 2007). Nevertheless, the exact locations where grazing should or should not occur are yet to be designated. Part of the animal protein produced in grasslands is difficult and unnecessary to replace as not all the grasslands are suitable for food production other than grazing (Van Zanten et al., 2018).

*** for the rest of the introduction, see the preprint here:

https://www.essoar.org/doi/10.1002/essoar.10505875.1

\section{Materials and methods}

We used remote sensing estimates of MODIS (Moderate Resolution Imaging Spectroradiometer) data products to estimate the carrying capacity (CC). We first extracted MODIS Land Cover Type product (Sulla-Menashe and Friedl, 2018; Table 1) and chose classes with significant grass cover, i.e. Woody savannas, Savannas and Grasslands according to the IGBP International Geosphere-Biosphere Programme) classification system. This grassland area comprises around $46 \%$ of the world's land area (excluding Antarctica). As land cover types might vary between years, we calculated the mode value (the land cover class that occurs most often) during 2010-2018 for defining the most common land cover type.

We followed the approach described by De Leeuw et al. (2019) to calculate aboveground biomass (AB) based on the $500 \mathrm{~m}$ resolution MODIS Net Primary Productivity (NPP) product (Running and Zhao, 2019; Table 1). First, we calculated the mean NPP during 2001-2019 and used a carbon conversion factor of 0.47 (Eggleston et al., 2006) to convert the original NPP values expressed as $\mathrm{kg} \mathrm{C} \mathrm{m-2} \mathrm{yr-1} \mathrm{to} \mathrm{biomass.} \mathrm{Since} \mathrm{plants} \mathrm{store} \mathrm{part}$ of their NPP in above ground biomass, we used the following formula (Eq. 1) developed for the grasslands (Hui and Jackson, 2006) to derive the fraction of the NPP (fANPP) allocated aboveground biomass: 
(1) $f_{A N P P}=0.171+0.0129$ MAT (Hui and Jackson, 2006)

where MAT is the Mean Annual Temperature in ${ }^{\circ} \mathrm{C}$. MAT for 1970-2000 was derived from WorldClim version 2 (Fick and Hijmans, 2017) and resampled to $500 \mathrm{~m}$ resolution.

Trees in savannas and woody savannas compete with grass and reduce its productivity. We reviewed the literature related to the effect of the tree canopy cover on the ground cover and the NPP of sub-canopy vegetation (De Leeuw and Tothill, 1990; Le Brocque et al., 2008; Lloyd et al., 2008; White et al., 2000). These studies revealed that an increase in the tree canopy cover results in a non-linear reduction in the sub-canopy cover, which reaches zero at tree canopy covers above $40-50 \%$. Based on this, we developed the following transfer function to translate the tree canopy cover into the fraction of NPP that is allocated to the sub-canopy.

(2) TreeCoverMultiplier $=-2.5 x^{2}-0.75 x+1$,

$x \in\{0,0.5\}, y \in\{1,0\}$,

where TreeCoverMultiplier refers to sub-canopy biomass and $\mathrm{x}$ refers to the percentage of the pixel area covered by the tree canopy. Here we used forest coverage data provided by Global Forest Change (Hansen et al., 2013; Table 1). Based on the function, we utilized the five tree canopy classes when reclassifying the original values and deriving the aboveground biomass of the understory (Figure 1). After the reclassification, the data was resampled to the resolution of the MODIS products. Thus, the final modified forest coverage data expresses the feed efficiency number for each forest pixel. The spatial extent of the forest coverage data $\left(180^{\circ} \mathrm{W}, 180^{\circ} \mathrm{E}, 60^{\circ} \mathrm{S}, 80^{\circ} \mathrm{N}\right)$ also determined the spatial extent of the study.

We further reduced this aboveground biomass by a slope steepness factor (see De Leeuw et al., 2019) to account for the risk erosion and avoid land degradation (Holechek et al., 2010).

*** for the rest of the materials and methods, see the preprint here:

https://www.essoar.org/doi/10.1002/essoar.10505875.1

\section{Results and interpretation}

\section{Aboveground biomass and carrying capacity}

The yields of the aboveground biomass are largest in low latitudes where there is also large spatial variation depending on the climatic zone. Near deserts, the $\mathrm{AB}$ may fall below $10 \mathrm{~g} \mathrm{~m}^{-2}$, whereas the most productive grasslands in the subtropics and tropics produce biomass over $500 \mathrm{~g} \mathrm{~m}^{-2}$ (Figure 2a). Notably large areas of high $\mathrm{AB}$ can be found in the eastern parts of South America and in East Africa (Figure 2a), where the NPP values are also the highest (Supplementary Figure S1).

\section{Relative stocking densities (RSD)}

On average, animal densities, as estimated by Gilbert et al. (2018), already concentrate in areas where the NPP and consequently the $\mathrm{CC}$ values are high. However, some of these regions are already overgrazed (e.g. Gaitán et al., 2018) or affected by degradation (Bai et al., 2008). Slightly more than half of the GLW3-modelled livestock population (nearly 2 billion AUs; see Supplementary Figure S2) is located in the areas we consider here as grasslands. This means that a considerable proportion of the livestock production (e.g. in India) is located outside of our study area (Figure 3, Supplementary Figure S2).

\section{CCs and RSDs in production system 'livestock-grazing'}

Our calculations cannot observe livestock consuming supplementary feed or account for all the variations in production systems ranging from extensive to intensive farming. Therefore, we estimated CCs and RSDs on grasslands, where the production system is 'livestock-grazing' (Robinson et al., 2011) as discussed in the methods section. These livestock-grazing grasslands comprise an area roughly corresponding to the IGBP land cover class 10, 'grassland', which contains broad and remote pasturage and extensive livestock production. It 
covers about one-third of our IGBP-based grassland area (classes 8,9 and 10) and approximately 240 million AUs inhabit these areas according to the GLW estimates (around 10\% of total AU). Consequently, CCs on these livestock-grazing grasslands make up around one-third of the total CC of all the grasslands.

*** for the rest of the results and interpretation, see the preprint here:

https://www.essoar.org/doi/10.1002/essoar.10505875.1

\section{Discussion and conclusion}

This study provides the first satellite observation-based global CC (carrying capacity) estimate of the world's grasslands. Our study provides much-needed high spatial resolution $(500 \mathrm{~m})$ data on $\mathrm{AB}$ (aboveground biomass) and CC, and a method to update these estimates regularly on a monthly and annual basis. Moreover, we assess the RSD (relative stocking density) on grasslands and livestock-grazing grasslands and discuss the reasons behind the regional differences in RSD. This information can be used in sustaining proper land management on grazing areas and rearranging the global food production in a sustainable way. These maps and findings can help identify undergrazed areas for targeted sustainable intensification efforts and assist with conservation efforts to reduce land degradation associated with overgrazing. Whilst our results imply that most parts of the world's grasslands fall within the low or medium pressure categories of RSD, we argue that grazing densities may not be increased in all of these regions. A notable share of the grasslands is currently overstocked and policy interventions might be needed to prevent unsupportable livestock management.

*** for the rest of the discussion and conclusion, see the preprint here:

https://www.essoar.org/doi/10.1002/essoar.10505875.1

\section{Dataset distribution}

The code used in the analyses will be published upon publication in GitHub. The derived datasets will be published in the Zenodo repository upon publication.

\section{Acknowledgements}

The work was funded by Maa- ja vesitekniikan tuki ry, the Emil Aaltonen Foundation -funded project 'eatless-water', the Academy of Finland -funded project WATVUL (grant No. 317320), and the European Research Council (ERC) under the European Union's Horizon 2020 research and innovation programme (grant agreement No. 819202).

\section{References}

Alkemade, R., Reid, R.S., van den Berg, M., de Leeuw, J., Jeuken, M., 2013. Assessing the impacts of livestock production on biodiversity in rangeland ecosystems. Proceedings of the National Academy of Sciences 110, 2090020905. https://doi.org/10.1073/pnas.1011013108

*** for the rest of the references, see the preprint here:

https://www.essoar.org/doi/10.1002/essoar.10505875.1 